\section{(2) OPEN ACCESS}

\title{
Patterns of negative seroconversion in ongoing surveys of SARS-CoV-2 antibodies among workers in New York's largest healthcare system
}

\author{
Grace Sembajwe (1), ${ }^{1}$ Rehana Rasul, ${ }^{2}$ Yehuda Jacobs, ${ }^{3}$ Keisha Edwards, ${ }^{3}$ \\ Lorraine Chambers Lewis, ${ }^{3}$ Tylis Chang, ${ }^{3}$ William Lowe, ${ }^{3}$ Jacqueline Moline ${ }^{4}$
}

\begin{abstract}
- Additional supplemental material is published online only. To view, please visit the journal online (http://dx.doi. org/10.1136/oemed-2021 107382)
\end{abstract}

'Occupational Medicine, Epidemiology, and Prevention, Northwell Health Feinstein Institutes for Medical Research, Great Neck, New York, USA Biostatistics and Occupational Medicine, Epidemiology, and Prevention, Northwell Health, Great Neck, New York, USA ${ }^{3}$ Employee Health Services and Core Laboratories, Northwell Health, New Hyde Park, New York, USA

${ }^{4}$ Population Health, Hofstra North Shore-LIJ School of Medicine, Great Neck, New York, USA

\section{Correspondence to} Health Feinstein Institutes for NY 11021, USA: gsembajwe@northwell.edu

Received 13 January 2021 Accepted 28 July 2021 Published Online First 25 August 2021 Dr Grace Sembajwe, Northwel Medical Research, Great Neck,

\section{ABSTRACT \\ Objectives Given the importance of continued} COVID-19 surveillance, our objective was to present findings from a short follow-up survey of workforce SARS-CoV-2 antibody testing in previously seropositive participants and describe associations between work locations and negative seroconversion.

Methods We conducted a follow-up cross-sectional survey on previously seropositive healthcare workers, using questionnaires and serology testing. Eligible employees previously consented to be contacted were invited by email to participate in a survey and laboratory blood draws. SAS V.9.4 was used to describe employee characteristics and seroconversion status. Binomial regression models were used to calculate unadjusted and adjusted prevalence ratios (PRs) of seronegativity. The multivariable analyses included age, gender, race/ ethnicity, region of residence, work location, prior diagnosis/PCR results and days between antibody tests. Unadjusted and adjusted PRs 95\% Cls and p values were reported.

Results Of the 3990 employees emailed in the follow-up, 1631 completed an exposure survey and generated a blood-draw requisition form. Average time between serology testing was 4 months. Of the 955 employees with complete serology results, $79.1 \%$ were female, $53.4 \%$ were white and $46.4 \%$ resided in Long Island; 176 participants seroconverted to negative. In multivariable regression analyses adjusted for gender, race/ethnicity and region of residence, younger employees $(<20-30$ years), intensive care unit workers and those with no/negative prior PCR results were more likely to have negative seroconversion.

Conclusions and relevance Patterns of negative seroconversion showed significant differences by sociodemographic and workplace characteristics. These results contribute information to workplace serosurveillance.

\section{INTRODUCTION}

(c) Author(s) (or their employer(s)) 2021. Re-use permitted under CC BY-NC. No commercial re-use. See rights and permissions. Published by BMJ.

To cite: Sembajwe $G$, Rasul R, Jacobs Y, et al. Occup Environ Med 2021:78:818-822.
Prior to the availability of vaccines for SARS-CoV-2 that causes COVID-19, exposure assessments through surveillance included antibody testing that allowed workplaces to understand prevalence patterns and potential exposure. ${ }^{12}$ As with many healthcare systems across the country, the largest one in New York implemented various COVID-19 policies that augmented infection control to increase the number of heating ventilation and

\section{Key messages}

What is already known about this subject?

- Antibodies for COVID-19 decline over time. However, population patterns of negative seroconversion are not well understood.

\section{What are the new findings?}

- The study discovered sociodemographic and workplace patterns of negative seroconversion among healthcare workers. In a follow-up survey of 955 previously seropositive New York healthcare workers, 176 retested negative over a 4-month study period. High negative seroconversion occurred among those with who had a negative or no prior PCR test, intensive care unit (ICU) workers (compared with non-ICU workers) and younger employees (20-29 years compared with other age groups).

How might this impact on policy or clinical practice in the foreseeable future?

- This is a large follow-up of seropositive healthcare workers, paired with a survey of work characteristics and self-reported exposures. Future directions include a review of vaccine uptake and seroconversion with molecular differentiation that includes an understanding of sociodemographic and workplace patterning of exposure over time.

air-conditioning inspections on floors and units, as well as adjusting specifications for aerosolising procedures and personal protective equipment (PPE) during patient handling. ${ }^{1-6}$ In spring 2020 (wave 1), our healthcare system offered free SARSCoV-2 antibody testing to all 70812 employees. ${ }^{2}$ Results of the testing have been previously reported for dates between 20 April 2020 and 23 June 2020. In brief, of the final consented participants (40 329), 13.7\% (5523) tested positive for IgG antibodies. ${ }^{2}$ The findings were comparable to New York State antibody screenings at the time, which revealed $12.3 \%$ of the general population were seropositive. $^{7-9}$ The New York State Governor's report at the time further showed $10.5 \%$ of the New York City Police Department and 17.1\% of New York City Fire Department Emergency 
Medical Service (FDNY/EMS) members had tested positive for antibodies. $^{29}$

Our healthcare system's wave 1 results showed that $93.7 \%$ of employees who were diagnosed positive through reverse transcription PCR tests were also positive for antibodies. ${ }^{2}$ Further, a self-reported index of suspicion of exposure to COVID-19 correlated well with antibody measures. This suggested that workers without confirmed PCR tests were attuned to degrees of exposure (online supplemental figure S1) and that the suspicion index was a robust measure of exposure perception. ${ }^{2}$ In the fall of 2020 (September and October) (wave 2), the healthcare system extended serology testing to 3990 employees, who were antibody positive in wave 1 and who agreed to future testing. This wave 2 serology testing introduced an opportunity to understand prevalence patterns in the workplace and target protective measures, as needed. Here, we present initial findings from a short exposure survey and the second round (wave 2, September and October 2020) of workforce testing for SARS-CoV-2 antibodies in participants previously identified as seropositive (wave 1, April and May 2020). Antibodies for COVID-19 decline over time. However, population patterns of negative seroconversion are not well understood. Given the importance of continued COVID-19 surveillance, our objective was to present findings from a short follow-up survey of workforce SARS-CoV-2 antibody testing in previously seropositive participants and describe associations between work locations and negative seroconversion.

\section{METHODS}

On 8 September 2020 (with reminders on 23 September 2020), 3990 emails were sent to eligible employees, who had initially tested positive for SARS-CoV-2 antibodies between April and June 2020 (wave 1) and who had consented to future serology testing. Some participants had received prior PCR testing. ${ }^{2}$ For this wave 2 study, blood draw requisitions and lab results were collected from 8 September 2020 to 5 October 2020. Antibody testing was validated at our healthcare system laboratories using a combination of ELISA, chemiluminescent microparticle immunoassays and immunometric assays. ${ }^{2}{ }^{10}$ These are instrumentbased, qualitative IgG SARS-CoV-2 immunoassays with up to $97 \%$ sensitivity. ${ }^{2}{ }^{10}$ The antibody test is not a test for active infection but may identify previous exposure to the virus within at least the past $1-2$ weeks. ${ }^{210}$ Additional information regarding the testing panels is available as online supplemental table S1.

Data collected from wave 2 testing were gathered, prepared and analysed for continued presence of SARS-CoV-2 antibodies. We used SAS V.9.4 software (SAS Institute Inc.) to conduct binomial regression analyses to calculate unadjusted and adjusted prevalence ratios (PRs) of seronegativity and frequency distributions for sociodemographic characteristics, work location, time between testing, county of residence, prior diagnosis/PCR, recent travel and level of suspicion of re-exposure to virus: 'Do you believe you may have been exposed again to COVID-19?' (1-9; $1=$ no; $9=$ yes definitely; $7-9=$ high suspicion of exposure). 'If so, did you feel ill?' (Yes/No). 'Do you usually take public transportation to work?' (Yes/No). 'In the past month, have you traveled outside of the NY metropolitan region and northeast?' (Yes/ No). Several industrial hygiene/infection control practices were noted, to include PPE policies (universal masking was required with N95 minimum for staff and procedural mask minimum for patients from as early as 7 March 2020; visitors were restricted and also required masking with temperature checks), ventilation requirements that adhered to American Society of Heating,
Refrigerating and Air-Conditioning Engineers recommendations with minimum air changes per hour ( $\mathrm{ACH}$ ) equal to $12-15$ for intensive care units (ICUs) that required minimum efficiency reporting values (13-14) to ventilate the rooms and positive pressure breathing apparatus (level B PPE). Patient waiting areas had a minimum recommendation of 4-6 $\mathrm{ACH}^{56}$

\section{RESULTS}

Of the 3990 wave 2 email invitations, 1631 employees responded to the survey and obtained requisitions, rendering a response rate of $40.9 \%$; of those, $955(58.6 \%)$ received wave 2 serology results and $779(81.6 \%)$ retested positive (table 1). Average months between testing were $4.3(\mathrm{SD}=0.5)$, median $=4.0$ and $\mathrm{IQR}=1$. Average age of non-participants in wave 2 was similar to that of participants. Blacks, Hispanics and males were less likely to participate in wave 2 (online supplemental table S2).

Overall negative seroconversion proportion was 176/955 $(18.4 \%(95 \% \mathrm{CI}=16.0 \%$ to $21.0 \%))$. In regression models that included age, gender, race/ethnicity, residential county, days between testing and prior PCR test, those working in areas other than the ICU were less likely to seroconvert to negative $(\mathrm{PR}=0.58,95 \% \mathrm{CI}=0.36$ to $0.93, \mathrm{p}=0.02)$, compared with ICU workers. Those who were previously seropositive and with a negative $\mathrm{PCR}$ result $(\mathrm{PR}=2.22,95 \% \mathrm{CI}=1.38$ to $3.59, \mathrm{p}=0.001)$ or no PCR test $(\mathrm{PR}=2.56,95 \% \mathrm{CI}=1.83$ to $3.58, \mathrm{p}<0.0001)$ were $2 \frac{1}{2}$ times more likely to seroconvert to negative than those with a positive PCR test (table 1). Residential and work counties, recent travel, transportation type and suspicion of re-exposure were not significantly associated with negative seroconversion.

\section{DISCUSSION}

Our results present patterns of negative seroconversion in a large, single study follow-up of previously seropositive healthcare workers. As expected, SARS-CoV-2 antibodies decreased over time. ${ }^{4}{ }^{10-12}$ Almost one-fifth of previously seropositive employees experienced negative seroconversion over a 4-month period.

Those working in ICUs were more likely to seroconvert (to negative) than employees in other work areas. Though not possible to confirm with this study, it is plausible that ICU locations have decreased potential for reinfection (exposure) because of effective infection control practices at work (increased ventilation checks and adherence to optimal standards, appropriate administrative polices and targeted PPE), low infection among coworkers, coupled with low prevalence of active community infection (at the time of wave 2 data collection, New York State had new daily infection rates below $1 \%) .{ }^{9}$ It is unclear why those over the age of 30 years were less likely to seroconvert to negative and thus, seemed to retain measurable SARS-CoV-2 antibodies for longer than younger workers. Similarly, those with confirmed disease through past PCR positive results were less likely to seroconvert to negative. The PCR testing for this cohort was conducted early in the pandemic (March/April 2020) when most tests were reserved for sicker, hospitalised individuals. It is conceivable that asymptomatic and those with milder symptoms were less likely to have received a PCR test.

There are limitations to these findings. This study sample was voluntary in waves 1 and 2 and results may not be generalisable to the population of all our seropositive healthcare workers. With wave 2 testing, there were patterns of non-response that may have influenced results. Determining the exact timeline between infection, antibody generation and antibody reduction was not possible because some employees were not diagnostically 


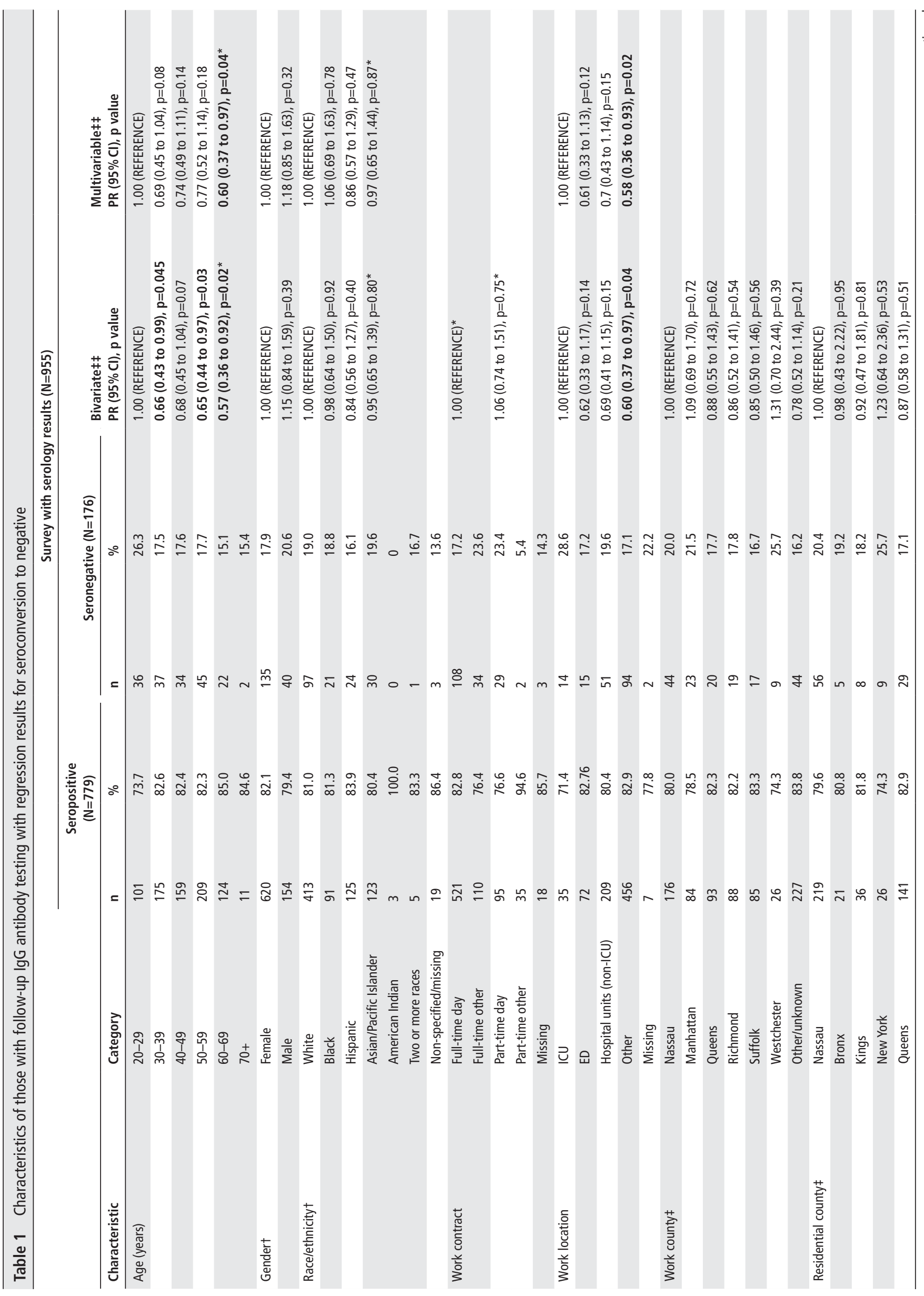




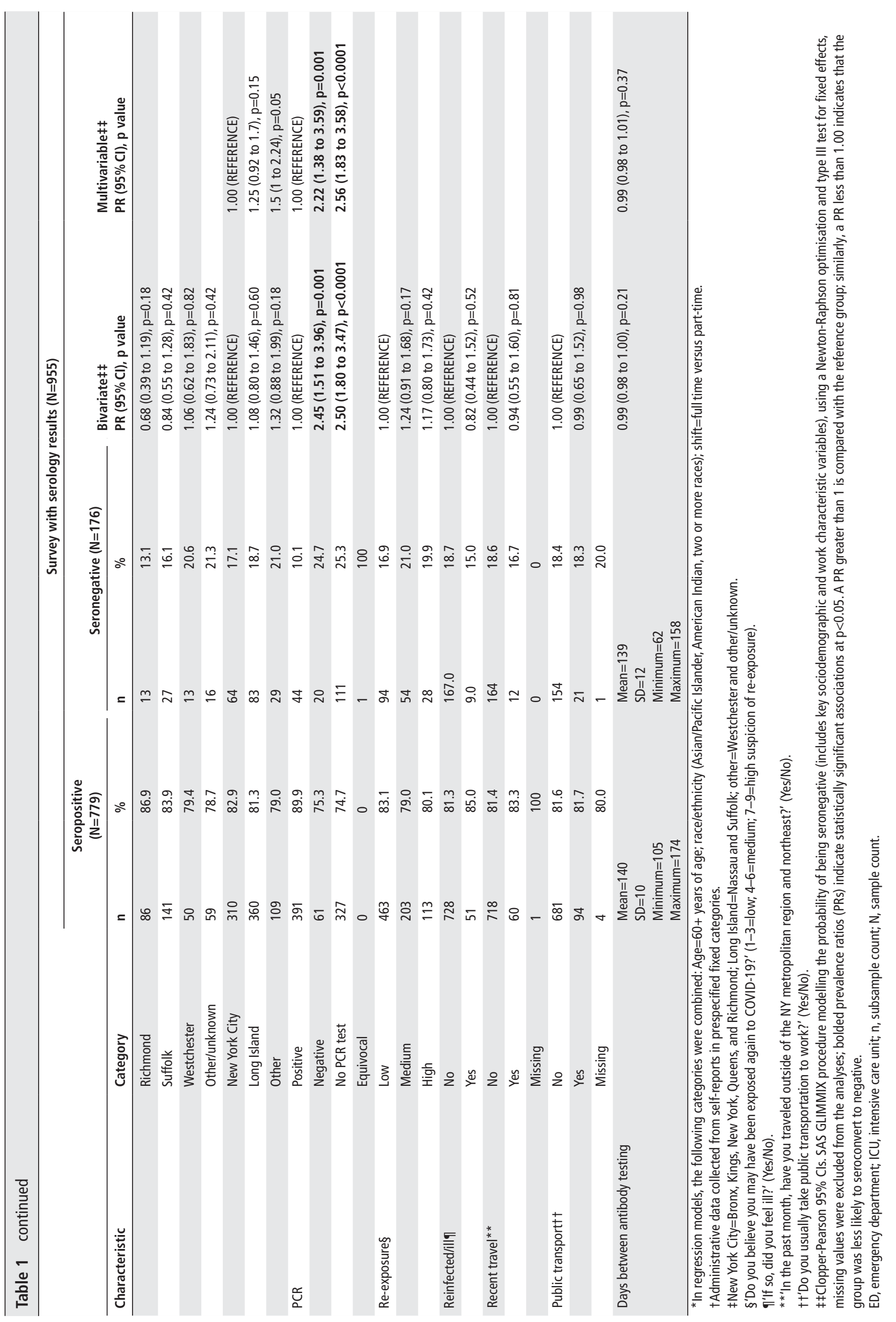


tested (PCR) at the time of infection. It is also possible that those who were more likely to seroconvert (to negative) during this follow-up were infected earlier than those who retained antibody seropositivity.

Nevertheless, these results are informative and document patterns of negative seroconversion in a sample of healthcare workers. This study also introduces exposure questions and biomarkers that will be expanded in future surveys. Sophisticated biological/molecular testing is particularly important as we begin to integrate vaccination results and patterns of infection.

Globally, frontline workers were among the hardest hit group early in the SARS-CoV-2 pandemic. $^{3}{ }^{4}$ In one of the largest cross-continental cohort studies that encompassed the UK and USA risk of reporting COVID-19 exposure or infection was highest among frontline healthcare workers. ${ }^{3}$ Data from New York showed variability by institute and county that may indicate community spread as the driver of these rates. ${ }^{2}$ In all studies, minority and socially disadvantaged groups were most affected and had among the highest prevalence of SARS-CoV-2 antibodies. ${ }^{12}$ Our results provide a summary of follow-up serology testing in New York State's largest workforce. Future directions include ongoing monitoring and analyses of the effects of vaccine delivery with a concerted outreach plan for healthcare workers and the surrounding communities.

\section{Twitter Grace Sembajwe @graces82 and Jacqueline Moline @drmoline}

Acknowledgements GS had full access to all the data in the study and takes responsibility for the integrity of the data and the accuracy of the data analysis. The authors wish to acknowledge the following colleagues who contributed through discussions and process development for data collection: Jonathan Amalfitano (Healthcare Analytics, Northwell Health, Lake Success, New York); Theresa Briggs, MBA (Healthcare Analytics, Northwell Health, Lake Success, New York); Maxine Carrington, JD (Northwell Health, New Hyde Park, New York); James Cuniglio (Northwell Health, New Hyde Park, New York); Karina Davidson, PhD, MASc (Feinstein Institutes for Medical Research, Northwell Health, Manhasset, New York); Bruce Farber, MD (Feinstein Institutes for Medical Research, Northwell Health, Manhasset, New York; Donald and Barbara Zucker School of Medicine at Hofstra/ Northwell, Northwell Health, Hempstead, New York; North Shore University Hospital/ Long Island Jewish Emergency Medical Department, Northwell Health, Manhasset, New York); Alan Fine, MS (Healthcare Analytics, Northwell Health, Lake Success, New York); Jennifer Grasso (Northwell Health, New Hyde Park, New York); Christopher J. Hutchins (Healthcare Analytics, Northwell Health, Lake Success, New York); Mark Jarrett, MD, MBA, Msc (Feinstein Institutes for Medical Research, Northwell Health, Manhasset, New York; Donald and Barbara Zucker School of Medicine at Hofstra/ Northwell, Northwell Health, Hempstead, New York; North Shore University Hospital/ Long Island Jewish Emergency Medical Department, Northwell Health, Manhasset, New York); Stefan Juretschko, PhD, D(ABMM) (Northwell Health Laboratories, Northwell Health, Lake Success, New York); Jaclyn LePage, BA (Northwell Health, New Hyde Park, New York); Joseph Moscola, PA, MBA (Northwell Health, New Hyde Park, New York); Evan Rousseau, MSc, CIH (Northwell Health, New Hyde Park, New York); Shuna Sun, MS, MBA (Healthcare Analytics, Northwell Health, Lake Success, New York); Howard Tuchman, BS, MBA (Healthcare Analytics, Northwell Health, Lake Success, New York), Christopher Zavala, BA, MBA (Northwell Health Laboratories, Northwell Health, Lake Success, New York) and Jill Zembera, PA, MPH (Northwell Health, New Hyde Park, New York).

Contributors Concept and design and critical revision of the manuscript for important intellectual content: all authors. Acquisition: GS and YJ. Drafting of the manuscript: GS. Statistical analysis: GS and RR. Obtained funding: LCL and JM. Administrative, technical or material support: GS, RR, YJ, KE, LCL and TC. Supervision: GS. The research personnel approved to prepare and analyse the data are GS, RR, TC and JM.
Funding This work was fully supported by Northwell Health. No grant number is available.

Competing interests None declared.

Patient consent for publication Not required.

Ethics approval This research was approved by our healthcare's institutional review board and allows for the use of administrative data and reconsenting for future blood draws and research.

Provenance and peer review Not commissioned; externally peer reviewed.

Data availability statement No data are publicly available. The data given are deidentified workforce data reported in the aggregate.

Supplemental material This content has been supplied by the author(s). It has not been vetted by BMJ Publishing Group Limited (BMJ) and may not have been peer-reviewed. Any opinions or recommendations discussed are solely those of the author(s) and are not endorsed by BMJ. BMJ disclaims all liability and responsibility arising from any reliance placed on the content. Where the content includes any translated material, BMJ does not warrant the accuracy and reliability of the translations (including but not limited to local regulations, clinical guidelines, terminology, drug names and drug dosages), and is not responsible for any error and/or omissions arising from translation and adaptation or otherwise.

Open access This is an open access article distributed in accordance with the Creative Commons Attribution Non Commercial (CC BY-NC 4.0) license, which permits others to distribute, remix, adapt, build upon this work non-commercially, and license their derivative works on different terms, provided the original work is properly cited, appropriate credit is given, any changes made indicated, and the use is non-commercial. See: http://creativecommons.org/licenses/by-nc/4.0/.

ORCID iD

Grace Sembajwe http://orcid.org/0000-0002-7163-4743

\section{REFERENCES}

1 Galanis P, Vraka I, Fragkou D, et al. Seroprevalence of SARS-CoV-2 antibodies and associated factors in healthcare workers: a systematic review and meta-analysis. $J$ Hosp Infect 2021;108:120-34

2 Moscola J, Sembajwe G, Jarrett M, et al. Prevalence of SARS-CoV-2 antibodies in health care personnel in the new York City area. JAMA 2020;324:893-5.

3 Nguyen LH, Drew DA, Graham MS, et al. Risk of COVID-19 among front-line healthcare workers and the general community: a prospective cohort study. Lancet Public Health 2020:5:e475-83.

4 Self WH, Tenforde MW, Stubblefield WB, et al. Decline in SARS-CoV-2 Antibodies After Mild Infection Among Frontline Health Care Personnel in a Multistate Hospital Network - 12 States, April-August 2020. MMWR Morb Mortal Wkly Rep 2020;69:1762-6.

5 Saran S, Gurjar M, Baronia A, et al. Heating, ventilation and air conditioning (HVAC) in intensive care unit. Crit Care 2020;24:194.

6 Facility Guidelines Institute, American Society for Healthcare Engineering. Guidelines for design and construction of hospitals and outpatient facilities. Chicago, IL: American Society for Healthcare Engineering, 2014

7 Havers FP, Reed C, Lim T, et al. Seroprevalence of antibodies to SARS-CoV-2 in 10 sites in the United States, March 23-May 12, 2020. JAMA Intern Med 2020. doi:10.1001/ jamainternmed.2020.4130. [Epub ahead of print: $21 \mathrm{Jul} 2020$ ].

8 Rosenberg ES, Tesoriero JM, Rosenthal EM. Cumulative incidence and diagnosis of SARS-CoV-2 infection in New York. Ann Epidemiol 2020.

9 New York state information on novel coronavirus. Available: https://www.governor. ny.gov/news/amid-ongoing-covid-19-pandemic-governor-cuomo-announces-resultscompleted-antibody-testing [Accessed 29 Dec 2020].

10 Crawford JM, Aguero-Rosenfeld ME, Aifantis I, et al. The new York state SARS-CoV-2 testing Consortium: regional communication in response to the COVID-19 pandemic. Acad Pathol 2021:8:237428952110068.

11 Ganz-Lord FA, Segal KR, Rinke ML. COVID-19 symptoms, duration, and prevalence among healthcare workers in the new York metropolitan area. Infect Control Hosp Epidemiol 2020:1-7.

12 Ibarrondo FJ, Fulcher JA, Goodman-Meza D, et al. Rapid decay of Anti-SARS-CoV-2 antibodies in persons with mild Covid-19. N Engl J Med 2020;383:1085-7. 